\title{
Urachal adenocarcinoma: a rare clinical presentation
}

\author{
Julia Pastorello ${ }^{1,2}$, Emanuela Lando ${ }^{2,3 *}$, Marina Ractz Bueno ${ }^{1,2}$, Camila dos Santos do Amaral ${ }^{1,2}$, \\ Cristiane Pagnussat Cechetti ${ }^{1,2}$
}

\begin{abstract}
${ }^{1}$ Department of Clinical Oncology, Hospital de Clínicas de Passo Fundo - HCPF, Passo Fundo, Rio Grande do Sul/ RS, Brazil.

${ }^{2}$ Academic League of Oncology and Hematology - LAONC- HCPF, Hospital de Clínicas de Passo Fundo - HCPF, Passo Fundo, Rio Grande do Sul/ RS, Brazil.

${ }^{3}$ Medical Student, Faculdade Meridional - IMED, Passo Fundo, Rio Grande do Sul/RS, Brazil.
\end{abstract}

Research Ethics Committee Approval (if necessary): We declare that the patient approved the study by signing an informed consent form and the study followed the ethical guidelines established by the Declaration of Helsinki.

Received on: Jul 27, 2021. Accepted on: Jul 31, 2021. Available online: Aug 2, 2021.

\begin{abstract}
Urachal tumor is extremely rare, since it is responsible for about $0.01 \%$ of all neoplasms already repeated in the history of clinical oncology, with the adenocarcinoma subtype being the most prevalent. Thus, the present work aims to report a case of a 55-year-old patient diagnosed with urachal tumor, relating the clinical presentation of the case according to current literary data. It was possible to show that such a diagnosis, as well as the institution of a standard treatment, is still a clinical challenge in modern medical practice.
\end{abstract}

Keywords: Oncology; Urology; Chemotherapy; Carcinogenesis.

\section{Introduction}

Urachal tumor is extremely rare, responsible for about $0.17 \%$ to $0.34 \%$ of the total bladder tumors, and for about $0.01 \%$ of all cases of malignant tumors, with the subtype adenocarcinoma related to $90 \%$ of your presentations [17]. Superior diagnostic prevalence among males, age range between the fourth and fifth decades of life, treatment varies according to clinical stage and surgery is of great relevance, systemic treatment, especially chemotherapy is reserved for stages in which metastatic involvement and tumor recurrence is evidenced [1-4]. Target therapy and immunotherapy, realities in several tumor subtypes, however few associated data were found in the treatment of uracal cancer.

The present study aims to report a rare presentation of a patient diagnosed with urachal adenocarcinoma, a literary review relating the data according to clinical presentation, which is extremely 
relevant and challenging in modern medical practice.

\section{Case report}

A female patient, 55 years old, hospitalized on an emergency basis due to pain in the lower abdominal region, associated with a palpable mass, presenting polyuria, dysuria and hematuria. Diagnostic / staging exams, computed tomography, (CT), showed a heterogeneous lesion with a solid cystic aspect, located in the midline of the pelvic cavity measuring $13.0 \times 8.5 \times 6.6 \mathrm{~cm}$ (Figure 1) associated with the thickening of then parietal thickening of intestinal loops. In addition to bladder involvement and uterine compression associated with signs of necrosis (Figure 1), a biopsy confirmed the diagnosis of urachal, mucosecretory adenocarcinoma.

During hospitalization, the condition worsened due to the presence of secretion in the infra-umbilical region of pure-bloody aspect, previously not manifested, thus performed procedure of implantation of urostomy bag, for control of associated mucinous secretion, which until the moment the patient is still in use.

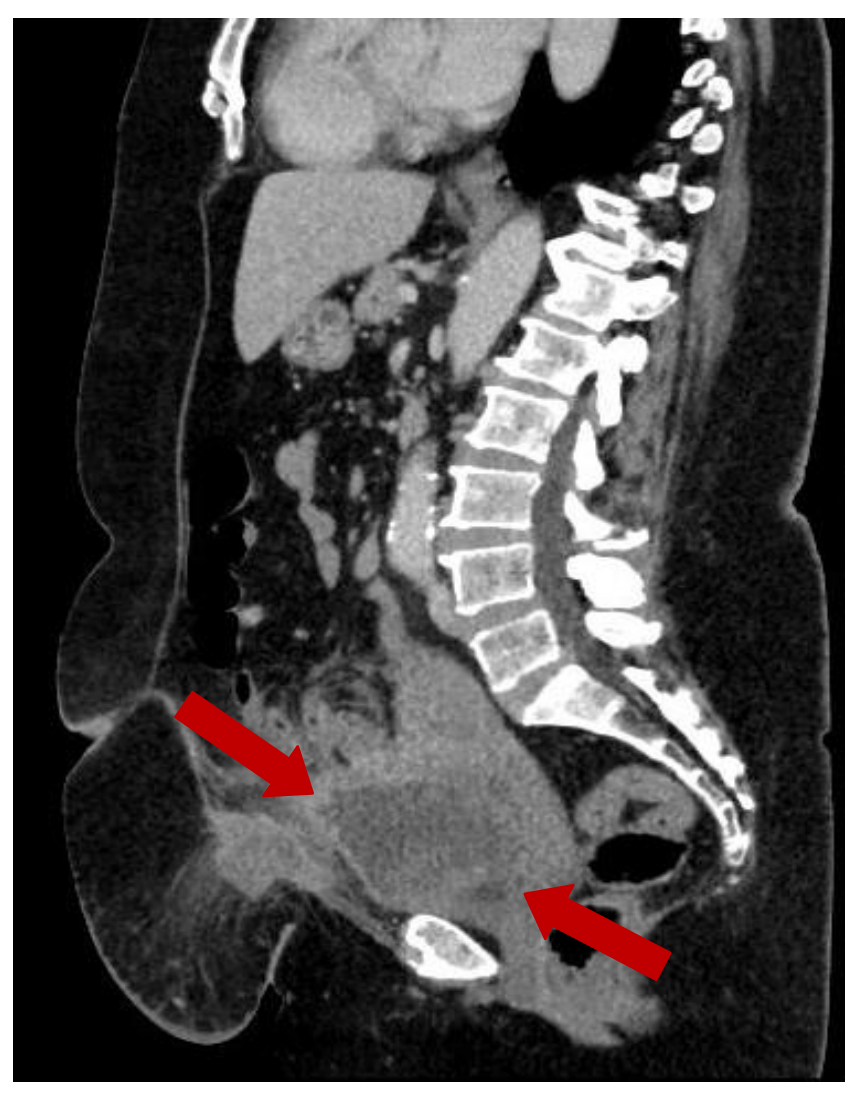

Figure 1: CT demonstrating, in red arrow, the heterogeneous lesion with a solid cystic aspect, in the midline of the pelvic cavity $(13.0 \times 8.5 \times 6.6 \mathrm{~cm})$ associated with the thickening of the adjacent adipose planes and segmental parietal thickening of intestinal loops, in addition to bladder involvement and uterine compression. 
However, a newly diagnosed patient with urachal neoplasia, cT4bN0M0, was not a candidate for surgical treatment due to locally advanced disease, being treated with chemotherapy based on paclitaxel, gemcitabine and cisplatin regimen. However, after a case of severe neutropenia, paclitaxel was excluded from the treatment regimen due to associated adverse effects.

Despite the recommended treatment line for the case, the patient presented little response, being a scheme based on FOLFOX (5-FU, leucovorin and oxaliplatin) instituted as a new therapeutic line for the case. However, the patient with a rare ongoing tumor diagnosis, has been presenting data that are consistent with the medical literature about the poor prognosis related to urachal adenocarcinoma.

The patient reported in this case has been followed since the beginning of the diagnosis of adenocarcinoma urachal, until the moment she is undergoing chemotherapy, which the last therapeutic line was changed.

\section{Discussion and Conclusion}

The urachus, also called the median umbilical ligament, is a remnant embryonic vestige of the cloaca and allantoid, derived from the urogenital sinus and the vitelline sac, respectively. It usually originates in the fourth or fifth month of embryonic development, through the contraction and obliteration of the allantois, which is responsible for the connection of the anterosuperior structure of the primitive fetal bladder to the umbilicus, measuring about 5 to 10 days, and after the phases of the adult life development is located between the medial umbilical ligaments, thus classified as median umbilical ligament [1-4].

Since such an embryonic trace remains in $30 \%$ of the world population, which can generate some anomalies, associated with pain in the suprapubic region, urinary symptoms evidenced mainly by the presence of hematuria associated with dysuria and increased urinary episodes $[1,3,5]$. However, cases of urachus tumor are extremely rare, responsible for about $0.17 \%$ to $0.34 \%$ of the total tumors of the bladder, and for about $0.01 \%$ of all cases of malignant tumors already described in the medical literature and current oncology [1,3,6-7].

Malignancy first described in 1863, with the adenocarcinoma subtype responsible for about $90 \%$ of its presentations, stratified according to associated histological characteristic, mucinous, intestinal, signet ring cells, mixed and unspecified [1-2,4,8-9].

Composed of an estimated incidence of 1 case per 5 million in the general population, proving associated diagnostic rarity [2,5-6,9], and higher diagnostic prevalence among males in about $67 \%$ of presentations, aged between 40 and 70 years [1-2,4].

Risk factors still little known and the diagnosis in most cases corroborate the poor prognosis associated [1-3,6]. Clinical presentation related to urachal tumor are the same as those previously mentioned in urachal anomalies, however, in the presence of activity, 
palpable suprapubic mass neoplasia can be evidenced, in addition to episodes of elimination of bloody or mucinous secretion eliminated by the umbilical pathway $[1,4]$.

The diagnosis is made through cystoscopy, in addition to imaging exams, which are essential to also assist in tumor staging, ultrasonography usually showing thickening of the anterosuperior structure, computed tomography (CT) showing supravesical mass and possible calcifications, magnetic resonance imaging as a complementary diagnostic method, and in some cases the PET-CT 18 F-FDG technique can be used for the same purpose $[1,4,10]$.

Classifications commonly used for staging follow the classification by Shelton and Henly, and the modified one by Henly (Mayo Clinic), most used in relation to the reported tumor subtype and TNM staging, all describing criteria of location, invasion, extension, lymphatic involvement and metastatic tumor in progress $[2,4,7,11-$ 12].

In relation to the associated metastatic activity, about $16 \%$ to $32 \%$ of the reported tumor subtype presents such impairment evidenced at diagnosis, mainly in the bone, bladder, pulmonary and lymph node regions. Survival associated with the tumor subtype ranges from $43 \%$ to $70 \%$ in 5 years, with the associated time between metastatic development and the lethality of urachal tumor being around 12 months, corroborating with poor prognosis data associated with cancerous disease [12-14].
Regarding treatment, the partial cystectomy procedure has a very significant result, still being considered the technique of choice, and the associated regional lymphadenectomy is still considered controversial. However, when metastatic disease is evidenced, locally recurrent and specific cases, systemic treatment should be instituted $[2,7,15]$. As the main systemic therapy, cisplatin-based chemotherapy is widely used alone or associated with methotrexate, vinblastine (CMV), metrotexate, vinblastine, doxorubicin, cyclophosphamide (MVAC), or cisplatin-5-FU-gemcitabine. In addition, paclitaxel, associated with cisplatin and ifosfamide also show evidence in the associated chemotherapy treatment, since by presenting some immunohistochemical similarities with colon cancer, treatments based on chemotherapy scheme FOLFOX (5-FU, leucovorin and oxaliplatin) and FOLFIRI (5-FU, leucovorin with irinotecan), can also be instituted [1620].

American study, carried out by Siefker-Radtke et al. [21], composed of 20 patients diagnosed with urachal neoplasia, undergoing chemotherapy regimen obtained 4 partial or complete responses, considering that of these 3 patients followed a chemotherapy regimen based on 5- FU and cisplatin [21].

According to Galsky et al. [22], based on a prospective American study, composed of 6 patients with urachal tumor, therapy based on cisplatin, paclitaxel and ifosfamide, it was 
associated with a $35 \%$ response rate and a stipulated average survival gain of 24.8 months [22].

Korean retrospective study, carried out by Hong et al. [23], which was composed of 21 patients with bladder carcinoma, of which included 4 patients with urachal neoplasia, evaluated the associated treatment in 11 patients based on regimen of ciscitabinecisplatin, 5 FU-cisplatin, paclitaxel, MVAC, CMV and VIP (etopisidio, ifosfamida, cisplatina) obtaining a response rate of $33 \%$ associated with an average survival of 13 months [23].

Another Korean study, being considered the most recent, carried out by Jung et al, composed of 10 patients with urachal neoplasia who were submitted to 24 different chemotherapy therapies of palliative character, it was possible so far to show a response rate of $16.7 \%$, and the therapy based on 5 $\mathrm{FU}$, gemcitabine and taxane was the most used among the modalities performed [18].

Targeted therapy, based on epidermal growth factor receptor (EGFR) inhibitors as similarly related to colorectal neoplasia can be instituted, however little information has been found in the medical literature. Phase I study, coordinated by the Canadian Cancer Institute, found that gefitinib medication achieved a 55\% decrease in associated tumor size, being a new treatment option $[7,24]$.

Regarding immunotherapeutic treatment, no study has been published so far, for the status associated with incompatibility repair, a clinical benefit was predicted for the use of anti-PDL 1, however there is a need for confirmation of information $[7,25]$.

Regarding radiotherapy treatment of urachal neoplasia, as it is not very radio sensitive, there is still no evidence of benefit in clinical studies [2,6-7,15,26-27].

Thus, the present clinical case becomes relevant due to the diagnostic rarity associated with urachal tumor, related to $0.01 \%$ of all manifestations of malignancies already described in the medical literature [1,3,6-7]. Making the diagnosis and institution of standard treatment still a clinical challenge in modern medical practice.

\section{References}

[1] Costa TM, Santana RM, Souza AF, et al. Adenocarcinoma de úraco: relato de caso de um tumor incidental. Urominas. 2016;3(7):56-8.

[2] Cruz CLP, Fernandes GL, Natal $\mathrm{MRC}$, et al. Neoplasia de úraco: relato de caso. Radiol. bras. 2014;47(6):387-8. https://doi.org/ 10.1590/ 0100-3984.2013.1879

[3] NeuUro. Tumores de Úraco [Internet]. 2011 [cited 2021 Mar 17]. Available from: http:// neouro.com.br/ tratamentos/tumores-de-uraco/

[4] García Salazar N, Pérez Silva MM, et al. Carcinoma de úraco, una neoplasia maligna poco frecuente. Rev. méd. Urug. (En línea). 2018;34(1):124-33. http://dx.doi.org/10.29193/rmu.34.1.6

[5] Planelles Gómez J, Olmos Sánchez L, Sánchez Cuallado C, et al. Adenocarcinoma de úraco: presentación 
de dos casos. Rev. chil. Urol. 2018; 83(1):44-8.

[6] Silva CD, Quinta A, Oliveira M, et al. Carcinoma de úraco. Acta Urológica. 2009;26(2):164.

[7] Hamilou Z, North S, Canil C, et al. Management of urachal cancer: a consensus statement by the Canadian Urological Association and genitourinary medical oncologists of Canada. Can Urol Assoc J. 2020;14(3):E57. doi: 10.5489/cuaj.5946

[8] Sheldon C, Clayman R, González R, et al. Signet-Malignant urachal lesions. J Urol. 1984;131(1):1-8.

https://doi.org/10.1016/S0022-

5347(17)50167-6

[9] Barrientos SL, Poblete MT. Carcinoma de uraco. Cuad. Cir. 2000; 14:27-32.

[10] Zeman M, Silver E, Akin E. CT and PET Findings for Urachal Adenocarcinoma: A Case Report. Ann Clin Case Rep. 2017; 2:1252.

[11] Kumar N, Khosla D, Kumar R, et al. Urachal carcinoma: Clinicopathological features, treatment and outcome. J Cancer Res Ther. 2014;10(3):571-4.

[12] National Comprehensive Cancer Network (NCCN) Clinical Practice Guidelines in Oncology (NCCN Guidelines( ${ }^{\circledR)}$ - Bladder Cancer. 2021. [cited 2021 Mar 17]. Available from: https://www.nccn.org/professionals/phy sician_gls/default.aspx

[13] Wein, AJ, Kavoussi LR, Novick AC, et al. Campbell Walsh Urology. Neuropathic dysfunction of the lower urinary tract. 4th ed. USA: Elsevier Saunders; 2011.

[14] Vogelzang NJ, Scardino PT, Shipley WU, et al. Comprehensive Textbook of Genitourinary Oncology. 3rd ed. Philadelphia: Wolters Kluwer Health/Lippincott Williams \& Wilkins; 2011.

[15] Koster IM, Cleyndert P, Giard RW. Best cases from the AFIP: urachal carcinoma. Radiographics. 2009; 29(3):939-42. https:// doi.org/ 10.1148/rg.293085152

[16] Peugniez C, Ghoneim T, Leroy X, et al. Les cancers de l'ouraqueUrachal cancers. Bull Cancer. 2013;100(5):509-17. doi: 10.1684/bdc.2013.1718

[17] Siefker-Radtke A. Urachal adenocarcinoma: A clinician's guide for treatment. Semin Oncol. 2012;39(5):61924. doi: 10.1053/j.seminoncol.2012.08.011 [18] Jung HA, Sun JM, Park SH, et al. Treatment outcome and relevance of palliative chemotherapy in urachal cancer. Chemotherapy. 2014;60(2):73-80. doi: $10.1159 / 000368071$

[19] Kikuchi M, Kamei S, Morirama Y, et al. Case of urachal cancer treated by neoadjuvant chemotherapy with FOLFOX4 (oxaliplatin, 5-FU and leukovolin). Hinyokika

Kiyo. 2008;54(8):557-9. PMID: 18788447

[20] Kume H, Tomita K, Takahashi S, et al. Irinotecan as a new agent for urachal cancer. Urol Int. 2006;76(3):281-2. doi: $10.1159 / 000091635$

[21] Siefker-Radtke AO, Gee J, Shen YU, et al. Multimodality management of 
urachal carcinoma: The M.D. Anderson Cancer Center experience. J Urol. 2003;169(4):1295-8. doi: 10.1097/ 01.ju.0000054646.49381.01

[22] Galsky MD, Iasonos A, Mironov S, et al. Prospective trial of ifosfamide, paclitaxel, and cisplatin in patients with advanced non-transitional cell carcinoma of the urothelial tract. Urology. 2007;69(2):255-9. doi: 10.1016/j.urology.2006.10.029

[23] Hong JY, Choi MK, Uhm JE, et al. Palliative chemotherapy for nontransitional cell carcinomas of the urothelial tract. Med Oncol. 2009;26(2): 186-92. doi: 10.1007/s12032-008-9106-7

[24] Goss G, Hirte H, Miller WH Jr, et al. A phase 1 study of oral ZD 1839 given daily in patients with solid tumors: IND.122, a study of the Investigational New Drug Program of the National Cancer Institute of Canada Clinical Trials Group. Invest New Drugs. 2005; 23(2):147-55. doi: 10.1007/ s10637-0055860-y

[25] Le DT, Uram JN, Wang H, et al. PD1 blockade in tumors with mismatchrepair deficiency. $\mathrm{N}$ Engl J Med. 2015;372(20):2509-20. doi: 10.1056/ NEJMoa1500596

[26] Ashley RA, Inman BA, Sebo TJ, et al. Urachal carcinoma: clinicopathologic features and long-term outcomes of an aggressive malignancy. Cancer. 2006;107(4):712-20. https:// doi.org/ 10.1002/cncr.22060

[27] Esteves FP, Pinto AC, Pinto AFC. Urachal adenocarcinoma. Braz J Urol. 2001;27(6):560-2.
Conflict of interest: The author declares no conflicts of interest.

Acknowledgements: We thank very much the whole team for the excellent multidisciplinary management of the case, especially Dr. Giovana Zerwes Vacaro, Dr. Nicoli Henn and the patient and or the responsible person for having trusted in our work and accepting the publication of this case report.

Funding: The author declares no funding to develop this article.

How to cite this article: Pastorello J, Lando E, Bueno MR, Amaral CS, Cechetti CP. Urachal adenocarcinoma: a rare clinical presentation. Brazilian Journal of Case Reports. 2021 Jul-Sep; 01(3):59-65. 